\title{
PALMERSTON AND THE ENGLISH OLIGARCHY, Karl Marx
}

Nesta seção TEORIA CLÁSSICA SOBRE O NEPOTISMO apresentamos um importante artigo de Karl Marx sobre as oligarquias familiares britânicas no governo de Lorde Palmerston, em 1855. Publicado pela primeira vez no Neue Oder-Zeitung, $\mathrm{n}^{\mathrm{o}} 105$, 3 de março de 1855. Escrito em 27 de fevereiro de 1855. Marx analisa minuciosamente a presença e o papel de famílias políticas na formação governamental, dentro da mesma lógica social de observar e investigar como as famílias no poder atravessam várias instituições com seus interesses.

O texto foi apresentado em língua inglesa, com o título "Palmerston and the English Oligarchy", no livro da Biblioteca do NEP - Karl Marx and Frederick Engels - On Britain, Second Edition, 1962. Foreign Languages Publishing House. Moscow. O texto também está disponível em inglês no Source: Marx and Engels Collected Works, Volume 14 (pp.49-52), Progress Publishers, Moscow 1980. MarxEngles.publicarchive.net \#ME0856en.html. Traduzido com o Google tradutor e outros com supervisão técnica do professor Ricardo Costa de Oliveira $^{1}$ e equipe NEP.

\section{Palmerston[1]}

Londres, 27 de fevereiro. O clamor contra a aristocracia foi respondido ironicamente por Palmerston com um ministério de dez lordes e quatro baronetes, dez - lordes, além disso, dos quais oito se sentam na Câmara dos Lordes. Ele encontrou a insatisfação ocasionada pelo compromisso entre as várias facções da oligarquia com um compromisso entre várias famílias dentro do grupo Whig. Para o clã Grey, a família ducal Sutherland e, finalmente, a família Clarendon receberam indenização em seu ministério. Sir George Gray, o Secretário do Interior, é primo de Earl Grey, cujo cunhado é Sir Charles Wood, Primeiro Lorde do Almirantado. O Conde Granville e o Duque de Argyll representam a família Sutherland. Sir George Cornwall Lewis, chanceler do Tesouro, é cunhado do conde de Clarendon, o ministro das Relações Exteriores. Só a Índia foi destinada a um homem sem

\footnotetext{
${ }^{1}$ Professor no Programa de Pós-Graduação em Sociologia, Universidade Federal do Paraná. Coordenador do Núcleo de Estudos Paranaenses (NEP). Contato: rco@uol.com.br
} 
título, Vernon Smith; mas de qualquer forma ele se casou com uma das famílias Whig. "Um reino por um cavalo!" gritou Richard III [a]. "Um cavalo por um reino!" grita Palmerston, imitando Calígula, e faz de Vernon Smith o Grande Mogul da Índia [2].

"Lorde Palmerston nos deu não apenas a administração mais aristocrática da qual temos qualquer exemplo na história do país", reclama The Morning Advertiser, "mas ele construiu seu governo com os piores materiais aristocráticos que ele poderia ter escolhido".

O anunciante digno, no entanto, encontra conforto no fato de que "Palmerston não é um agente livre. [...] Ele ainda está em grilhões e obrigações".

Como previmos [c], Lorde Palmerston formou um gabinete de cifras, ele mesmo sendo a única figura nele. Lorde John Russell, que em 1851 o derrubou de forma não-diplomática do gabinete Whig, foi enviado diplomaticamente por ele em uma viagem [3]. Palmerston fez uso dos Peelites para entrar na herança de Aberdeen. Assim que teve a certeza de que o primeiro-ministro deixaria os Aberdeenites [d] e roubou de Russell, como diz Disraeli, não apenas as roupas dos Whigs, mas os próprios Whigs [e]. Apesar da grande semelhança, quase identidade, do atual governo e da administração de Russell Whig, de 1846 a 1852, nada poderia ser mais errado do que confundi-los. Desta vez não temos um gabinete a não ser Lord Palmerston em vez de um gabinete. Embora seus membros sejam basicamente os mesmos de antes, os postos foram distribuídos entre eles de tal maneira, seus seguidores na Câmara dos Comuns são tão diferentes e estão aparecendo sob circunstâncias tão completamente mudadas que, enquanto antes, era um ponto fraco. $\mathrm{O}$ ministério whig é agora a forte ditadura de um só homem, desde que Palmerston não seja um espúrio Pitt, Bonaparte, nem um Napoleão espúrio, e Lorde John Russell continue a viajar. Embora o burguês inglês tenha ficado incomodado com a reviravolta inesperada dos acontecimentos, ele se diverte atualmente com a falta de habilidade com que Palmerston enganou tanto o amigo quanto o inimigo. Palmerston, diz o comerciante da cidade, mais uma vez provou-se "inteligente" [f]. Mas "inteligente" é uma qualificação intraduzível, cheia de ambigüidade e rica em conotações. Compreende todos os atributos de um homem que sabe como tocar sua própria trombeta e compreende o que lhe dá lucro e o que agride os outros. Por mais virtuoso e respeitável que seja o burguês inglês, ele admira a maioria dos homens "espertos", que não se importam com a moral, que não se desconcerta com respeito, que considera os princípios como armadilhas para prender seus 
companheiros. Se Palmerston é tão "inteligente", ele não irá despistar os russos da mesma maneira que superou Russell? Assim fala o político da alta classe média inglesa.

Quanto aos Conservadores, eles acreditam que os bons velhos tempos estão de volta, o feitiço da coalizão malvada foi quebrado e a tradicional gangorra governamental Whig e Tory foi restaurada. Uma mudança real, não confinada a uma mera dissolução passiva, poderia, de fato, acontecer apenas sob um governo conservador. Somente quando os Conservadores estão no comando é uma tremenda pressão vinda do exterior e as inevitáveis transformações são postas em prática. Por exemplo, a emancipação dos católicos durante o ministério de Wellington; a revogação das Leis do Milho durante o ministério de Peel; e o mesmo era verdadeiro, se não da Lei de Reforma, pelo menos da agitação da reforma, que era mais importante do que seu resultado. [4]

Quando os ingleses pediram a um holandês que viesse especialmente do outro lado do mar para se tornar seu rei [h], foi com o propósito de dar início à nova dinastia uma nova época - a época da associação da aristocracia fundiária com a aristocracia financeira. Desde então, encontramos o privilégio concedido pelo sangue e pelo privilégio concedido pelo ouro em equilíbrio constitucional. O sangue, por exemplo, decide no caso de certos postos do exército, cujos titulares os mantêm em virtude de conexões familiares, nepotismo ou favoritismo; mas o ouro é devido, pois todas as comissões do exército podem ser compradas e vendidas em dinheiro. Calculou-se que os oficiais que agora servem nos vários regimentos investiram um montante de 6 milhões de libras em seus postos. A fim de não perder os direitos que adquiriram durante o seu serviço e de não serem demitidos de seus empregos por alguns jovens sacos de dinheiro, os policiais mais pobres tomam dinheiro emprestado para garantir seu progresso e, assim, ficam sobrecarregados com hipotecas.

$\mathrm{Na}$ igreja, como no exército, conexões familiares e dinheiro em caixa são os dois fatores que contam. Enquanto parte dos ofícios eclesiásticos é destinada aos filhos mais jovens da aristocracia, a outra parte pertence ao maior lance. O comércio das "almas" do povo inglês - na medida em que pertencem à Igreja estabelecida - não é menos comum do que o tráfico de escravos na Virgínia. Neste comércio existem não só compradores e vendedores, mas também corretores. Um tal corretor "clerical", chamado Simpson, apareceu ontem perante a Corte do Banco da Rainha [i] [5] para exigir a taxa devida a ele de um certo Lamb, que, segundo ele, havia contratado para obter o direito de ter o reitor 
Josiah Rodwell apresentado para o benefício da paróquia de West-Hackney. Simpson havia estipulado 5\% do comprador e do vendedor, além de algumas pequenas despesas. Lamb, ele disse, não cumpriu suas obrigações. As circunstâncias eram as seguintes: Lamb é filho de um reitor de setenta anos que possui dois benefícios em Sussex, cujo preço de mercado é estimado em $£ 16.000$. O preço é naturalmente proporcional ao rendimento da paróquia e em proporção inversa à idade do ocupante. Lamb Júnior é o patrono dos vivos mantidos por Lamb Senior e também é irmão de um Lamb ainda mais jovem, o dono dos vivos e reitor de West-Hackney. Como o reitor de West-Hackney ainda é muito jovem, o preço de mercado da próxima apresentação à sua sinecura é relativamente baixo. Embora ela forneça uma renda anual de $£ 550$, bem como uma reitoria, seu dono concordou em vender o direito ao próximo compromisso por apenas $£ 1.000$. Seu irmão prometeu a ele que as paróquias de Sussex após a morte de seu pai, mas quer vender sua assim desocupada vida em West-Hackney através de Simpson para Josiah Rodwell por $£$ 3.000, embolsando um lucro líquido de $£ 2.000$, e seu irmão obtendo um melhor benefício. $\mathrm{O}$ corretor teria recebido uma comissão de $5 \%$, ou seja, £ 300 . Não aconteceu porque o acordo não foi aprovado. O tribunal concedeu ao corretor Simpson $£ 50$ em compensação "pelo trabalho realizado".

\section{Notas}

[a] Shakespeare, Ricardo III, Ato V, Cena 4. - Ed.

[b] "O Ministério dos Títulos", The Morning Advertiser, No. 19872, 28 de fevereiro de 1855.

[c] Veja naquele volume, p. 45.Ed.

[d] Graham, Gladstone e Herbert. - Ed.

O discurso de Disraeli na Câmara dos Comuns em 28 de fevereiro de 1845. Debates parlamentares de Hansard, terceira série, vol. LXXVIII, Londres, 1845.

[f] Marx usa a palavra inglesa.-Ed.

[g] Marx usa as palavras inglesas "pressão de fora" e dá a tradução alemã.

[h] Guilherme de Orange. - Ed.

[i] "Tribunal da Rainha Bench. Guildhall, 26 de fevereiro", The Times, No. 21988, 27 de fevereiro de 1855. Marx dá o nome da corte em inglês. 
[1] Este artigo foi publicado pela primeira vez em inglês em Karl Marx e Frederick Engels, On Britain, Moscou, 1953 sob o título "Palmerston and the English Oligarchy". O título foi fornecido pelos editores.

[2] O imperador romano Calígula (12 a 41 d.C.) concedeu o consulado em seu cavalo favorito.

O Grande Mogul foi o nome dado pelos europeus aos governantes de um império fundado no norte da Índia em 1526 por conquistadores turcos então considerados descendentes dos guerreiros mongóis de Genghis Khan (daí o nome "Moguls"). Embora o império tenha caído em declínio no século XVIII e tenha sido dominado pelos britânicos, seus governantes mantiveram a soberania nominal até 1858 .

[3] Refere-se à nomeação de Russell como representante da Grã-Bretanha na Conferência de Viena, que deveria ser aberta em março de 1855.

[4] Emancipação dos católicos - em 1829, o Parlamento britânico, sob pressão de um movimento de massas na Irlanda, levantou algumas das restrições que restringem os direitos políticos da população católica. Os católicos tiveram o direito de ser eleitos para o Parlamento e ocupar certos cargos no governo. Simultaneamente, a qualificação da propriedade para os eleitores foi multiplicada por cinco. Com a ajuda dessa manobra, as classes dominantes britânicas esperavam conquistar ao seu lado a camada superior da burguesia irlandesa e dos proprietários de terras católicos e, assim, dividir o movimento nacional irlandês. Revogação das Leis do Milho.

O movimento de massas pela reforma parlamentar na Grã-Bretanha se desenvolveu no final da década de 1820 e início da de 1830, durante o Ministério Tory de Wellington. A reforma foi realizada pelo governo Whig de Grey (novembro de 1830 a julho de 1834).

[5] Tribunal da Rainha (King's Bench) — instituição judicial mais antiga da GrãBretanha. No século XIX (até 1873), era um tribunal superior independente para casos criminais e civis e também supervisionava os tribunais inferiores. Posteriormente, sua competência limitou-se a disputas civis.

Recebido em: 30 maio 2019.

Aceito em: 10 junho 2019. 